\title{
Os 500 anos do pai da Bibliografia: da celebração ao gesto bibliográfico de Conrad Gesner (2016-1516)
}

Andre Vieira de Freitas Araujo

Docente da Universidade Federal do Rio de Janeiro (UFRJ). Doutorando em Ciência da Informação Universidade de São Paulo (PPGCI-ECA-USP) / Período Sanduíche na Alma Mater Studiorum - Universidade de Bolonha (UNIBO). Bolsista da Coordenação de Aperfeiçoamento de Pessoal de Nível Superior (CAPES)

http://dx.doi.org/10.1590/1981-5344/3233

Parte da narrativa sobre as comemorações em torno dos 500 anos de nascimento de Conrad Gesner (1516-1565), com ênfase nas experiências vividas no International Congress Conrad Gessner, realizado em junho de 2016 em Zurique, Suíça. No contexto deste fórum de especialistas, identifica o perfil dos Estudos Gesnerianos, com destaque para as pesquisas ligadas à faceta bibliográfica do polímata suíço. A partir das celebrações de 2016, realiza um percurso histórico-retrospectivo ao Séc. XVI para situar e discutir, de forma preliminar, dois aspectos subjacentes ao gesto bibliográfico Gesneriano: método e implicações epistemológicas. Conclui que dimensão histórico-interpretativa da informação, que perpassa pelo gesto e método bibliográfico Gesneriano, não pode ser negligenciada para uma compreensão retrospectiva, crítica e ao mesmo tempo atual do campo informacional.

Palavras-chave: Bibliografia. Conrad Gesner (15161565). Estudos Gesnerianos. International Congress Conrad Gessner (2016). Método bibliográfico Gesneriano. 


\title{
The $\mathbf{5 0 0}$ years of the father of Bibliography: from the celebration to the bibliographic gesture of Conrad Gesner (2016-1516)
}

\begin{abstract}
The article begins with the narrative about the celebrations around Conrad Gesner's 500th birthday (1516-1565), with emphasis on the experiences of the International Congress Conrad Gessner, held in June 2016 in Zurich, Switzerland. In the context of this forum of experts, it identifies the profile of the Gesnerian Studies, with emphasis on the researches related to the bibliographic facet of the Swiss polymath. From the celebrations of 2016, it presents a historical-retrospective trajectory to 16th century to locate and discuss, in a preliminary way, two aspects underlying Gesner's bibliographic gesture: method and epistemological implications. It concludes that the historical-interpretative dimension of information, that permeates the gesture and Gesnerian bibliographic method, can not be neglected for a retrospective, critical and at the same time current understanding of the informational field.
\end{abstract}

Keywords: Bibliography. Conrad Gesner (1516-1565). Gesnerian bibliographic method. Gesnerian Studies. International Congress Conrad Gessner (2016).

Recebido em 31.05.2017 Aceito em 30.06.2017

\section{Introdução}

A Bibliografia encontra nos documentos a sua origem e seu desenvolvimento teórico-metodológico, visto que cria uma série de estratégias para o mapeamento, organização e representação documentária.

Enquanto disciplina, a Bibliografia não se reduz às propostas técnicas de enumeração documentária - embora estas técnicas sejam a matriz para o desenvolvimento de modelos práticos e conceituais para organização e mediação de documentos ao longo de distintos contextos histórico-culturais.

Portanto, para além do aspecto enumerativo dos documentos, a Bibliografia é o esquema da realidade destes. É aquilo que o bibliógrafo 
italiano Alfredo Serrai ${ }^{1}$ chama de evidência ordenada das referências relativas a tudo que já foi escrito e, eventualmente, publicado ou reproduzido (SERRAI, 2001).

A interpretação histórica do que seja o documento e a informação, que caminha ao lado das bases epistemológicas da Ciência da Informação, encontra na Bibliografia pilares que não podem ser negligenciados para uma compreensão retrospectiva e crítica do campo informacional.

Neste ponto é que o estudo de fontes e personagens, muitas vezes conhecidos, mas não investigados em profundidade, estimulam uma leitura histórica sobre o campo que permite o atravessamento de interpretações centralizadas somente nas experiências dos Sécs. XIX ao XXI.

Investigar a faceta bibliográfica de Conrad Gesner (1516-1565) nos permite justamente este atravessamento, uma vez que o seu gesto bibliográfico representou mudanças nas formas de produção, seleção, organização e mediação documentária na Europa Moderna. Ainda, não é exagero afirmar que a difusão da Ciência Moderna deve muito ao gesto bibliográfico de Gesner, considerando que inúmeras bibliografias se basearam no maior projeto bibliográfico fruto do Humanismo: Bibliotheca Universalis (1545) e as Pandectae (1548).

As contribuições de Gesner estão presentes em inúmeras áreas do conhecimento para além da Bibliografia, como a Botânica, Zoologia, Medicina, Filologia, Linguística, Teologia, Paleontologia etc. Isto resulta, na contemporaneidade, em um conjunto de estudos denominados Estudos Gesnerianos, que se ocupam de investigar as contribuições de um dos grandes cientistas do período moderno.

No Brasil, estudos específicos sobre Conrad Gesner, do ponto de vista da Bibliografia, são recentes ${ }^{2}$. Estes estudos podem abrir novas

1 Alfredo Serrai é Professor Titular de Bibliografia, Biblioteconomia e História das bibliotecas, aposentado desde 2008. É Professor Emérito de Bibliografia e História das Bibliotecas na Universidade dos Estudos de Roma. Após uma experiência como bibliotecário que o levou à direção da Biblioteca Casanatense entre 1976 e 1979 e da Biblioteca Alessandrina entre 1979 e 1980, foi Professor Titular na Universidade La Sapienza de Roma e na Escola Especial para Arquivistas e Bibliotecários desempenhando, nessa última, papel de Diretor entre 1987-88 e 1989-90. Fundador e diretor, entre 1984 e 1998, e entre 2008 e 2011 (ano em que encerraram as publicações) da Revista Il bibliotecario. Em 2002 foi co-fundador da revista Bibliotheca, que dirigiu até 2007, ano de encerramento das publicações. Atualmente é co-diretor responsável do periódico Bibliothecae.it. Em plena atividade intelectual, publicou recentemente os livros La bibliografia come febre di conoscenza: una conversazione con Marco Menato e Simone Volpato (2015) e La biblioteca tra informazione e cultura (2017). É autor de dezenas de livros publicados pelas editoras Sylvestre Bonnard, Forum, Olschki, Sansoni, Bottega d'Erasmo, Istituto Poligrafico e Zecca dello Stato, Editrice Bibliografica. Sua obra principal é a monumental Storia della Bibliografia, publicada em onze volumes e em treze tomos, entre os anos de 1988 e 2001, pela Bulzoni de Roma. A obra discute a construção histórico-filosóficoconceitual da Bibliografia, por meio de uma pesquisa histórica rigorosa dos produtos documentários e de seus autores, sem desconsiderar o mapeamento e a representação dos saberes e do conhecimento no contexto das ciências e das instituições. No núcleo da obra está a história dos, hoje chamados, processos informacionais e comunicacionais.

${ }^{2}$ Estudos brasileiros específicos sobre Conrad Gesner, sob o viés da Bibliografia, podem ser verificados em: 1) ARAUJO, Andre Vieira de Freitas; CRIPPA, Giulia. Cultura bibliográfica e documento no séc. XVI: Bibliotheca Universalis. In: COLÓQUIO INTERNACIONAL DA REDE MUSSI: as transformações do documento no espaçotempo do conhecimento, 3, 2014, Salvador, BA. Anais... Salvador: Rede Mussi, 2014. CD Rom.; 2) ARAUJO, Andre Vieira de Freitas. Pioneirismo bibliográfico em um polímeta do Séc. XVI: Conrad Gesner. Informação \& Informação, Londrina, v. 20, n. 2, maio/ago. 2015. Disponível em: <http://www.uel.br/revistas/uel/index.php/informacao/article/view/23127>. Acesso em: 15 ago. 2015.; 3) 
possibilidades interpretativas não somente à Bibliografia Histórica, mas à própria Bibliografia e a sua relação com campos histórica e epistemologicamente correlatos como a Documentação, Biblioteconomia e Ciência da Informação.

O ano de 2016 foi significativo para os Estudos Gesnerianos, pois foi o ano em que se comemorou os 500 anos do nascimento de Conrad Gesner, por meio da concepção e realização de uma série de eventos e ações em homenagem ao nascimento do polímata suíço.

Neste contexto, destaca-se a realização do International Congress Conrad Gessner, cujo objetivo foi reunir especialistas de países diversos para debater e difundir as contribuições de Gesner em diferentes áreas do conhecimento.

Neste artigo, partimos da narrativa sobre as comemorações em torno dos 500 anos de nascimento de Conrad Gesner com ênfase nas experiências vividas no International Congress Conrad Gessner, realizado de 06 a 09 de junho de 2016 em Zurique, Suíça.

No contexto deste fórum de especialistas, identificamos o perfil dos Estudos Gesnerianos, com destaque para as pesquisas ligadas à faceta bibliográfica de Gesner.

Posteriormente, a partir das celebrações de 2016, realizamos um percurso histórico-retrospectivo ao Séc. XVI para situar e discutir, de forma preliminar, dois aspectos subjacentes ao gesto bibliográfico Gesneriano: método e implicações epistemológicas.

\section{Breve perfil de Conrad Gesner}

Conrad Gesner (FIG. 1) nasceu em 16 de março de 1516, em Zurique, e faleceu em 13 de dezembro de 1565, também em Zurique.

Foi uma figura multifacetada que dominou diversas disciplinas, tornando-se conhecido por estudar a fauna e flora dos Alpes Suíços.

\footnotetext{
ARAUJO, Andre Vieira de Freitas; CRIPPA, Giulia. A dimensão histórico-epistemológica da Organização do Conhecimento: contributos da taxonomia gesneriana, Séc. XVI. In: GUIMARÃES, José Augusto; DODEBEI, Vera. (Org.). Organização do Conhecimento e Diversidade Cultural (Estudos Avançados em Organização do Conhecimento, v. 3). Marília: ISKO-Brasil; FUNDEPE, 2015, v. 3, p. 37-46.; 4) ARAUJO, Andre Vieira de Freitas; CRIPPA, Giulia. Confusa e irritante multidão de livros: relações entre o contexto histórico-informacional da Europa Moderna e a estrutura documentária de Bibliotheca Universalis, de Conrad Gesner. InCID: Revista de Ciência da Informação e Documentação, v. $\quad 7$ p. 2016. <http://www.revistas.usp.br/incid/article/view/118774>. Acesso em: 20 fev. 2016.; 5) ARAUJO, Andre Vieira de Freitas; CRIPPA, Giulia; SABBA, Fiammetta. Semantic order in the 16th century: an introductory discussion of Conrad Gesner's Pandectae. In: GUIMARAES, José Augusto Chaves Guimarães. (Org.). Knowledge Organization for a sustainable world: challenges and perspectives for cultural, scientific, and technological sharing in a connected society. Proceedings of the Fourteenth International ISKO Conference, Sep. 2729, 2016, Rio de Janeiro, Brasil. Würzburg: Ergon Verlag, 2016; 6) ARAUJO, Andre Vieira de Freitas. Conrad Gesner in the tropics: the presence of Bibliotheca Universalis and Pandectae in two Brazilian heritages libraries. In: LEU, Urs. (Org.).International Congress Conrad Gessner. Zürich: Universität Zürich, 2018 (no prelo).
} 


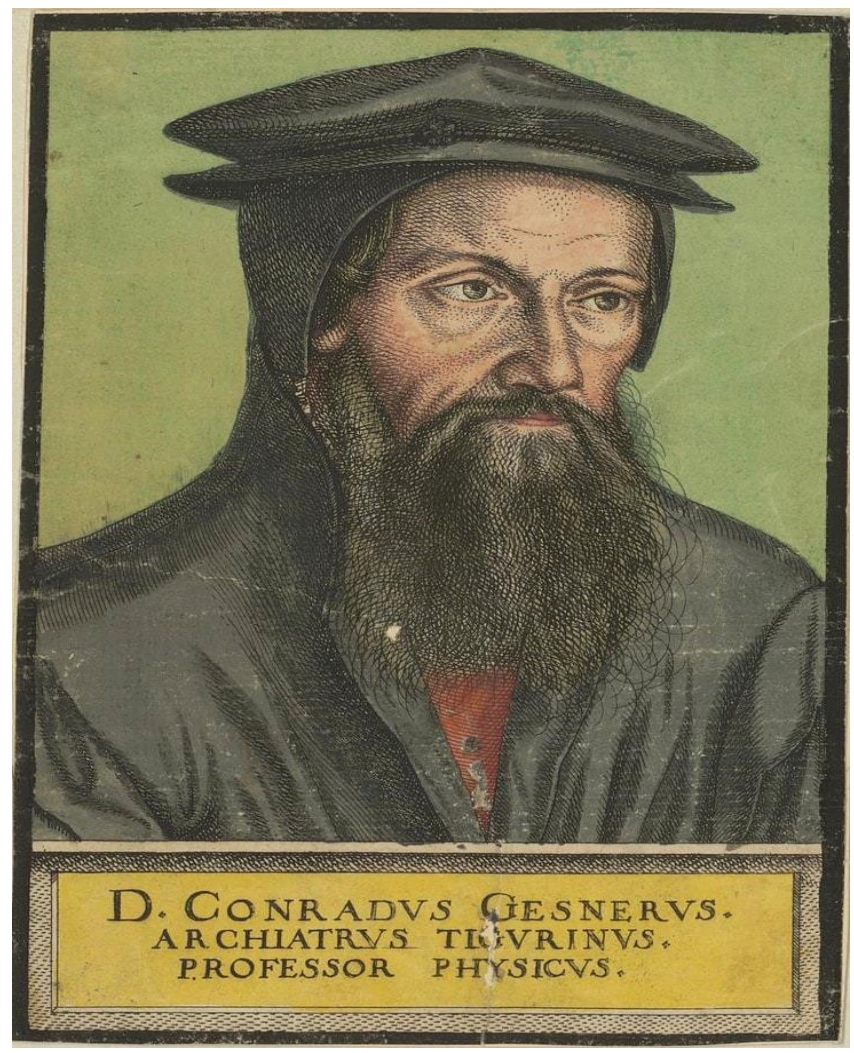

Figura 1 - Conrad Gesner

Fonte: D. CONRADUS Gesnerus (16--?).

Acesso em: <http://www.e-rara.ch/zuz/periodical/titleinfo/12276926>

No campo da Botânica, Gesner publicou Catalogus Plantarum (1542), um catálogo de plantas, como o nome já indica, em quatro idiomas (latim, grego, alemão e francês) (FIG. 2). A obra demonstra o crescente interesse de Gesner pela Botânica, bem como incursões de ordem filológica sobre os escritos clássicos (GESNER, 1542).

Sua organização principal é por ordem alfabética de nomes das plantas, o que evidencia o esforço de Gesner em organizar tópicos científicos em ordem alfabética ou sistemática. Isto demonstra a vocação de Gesner para elaboração obras bibliográficas. 


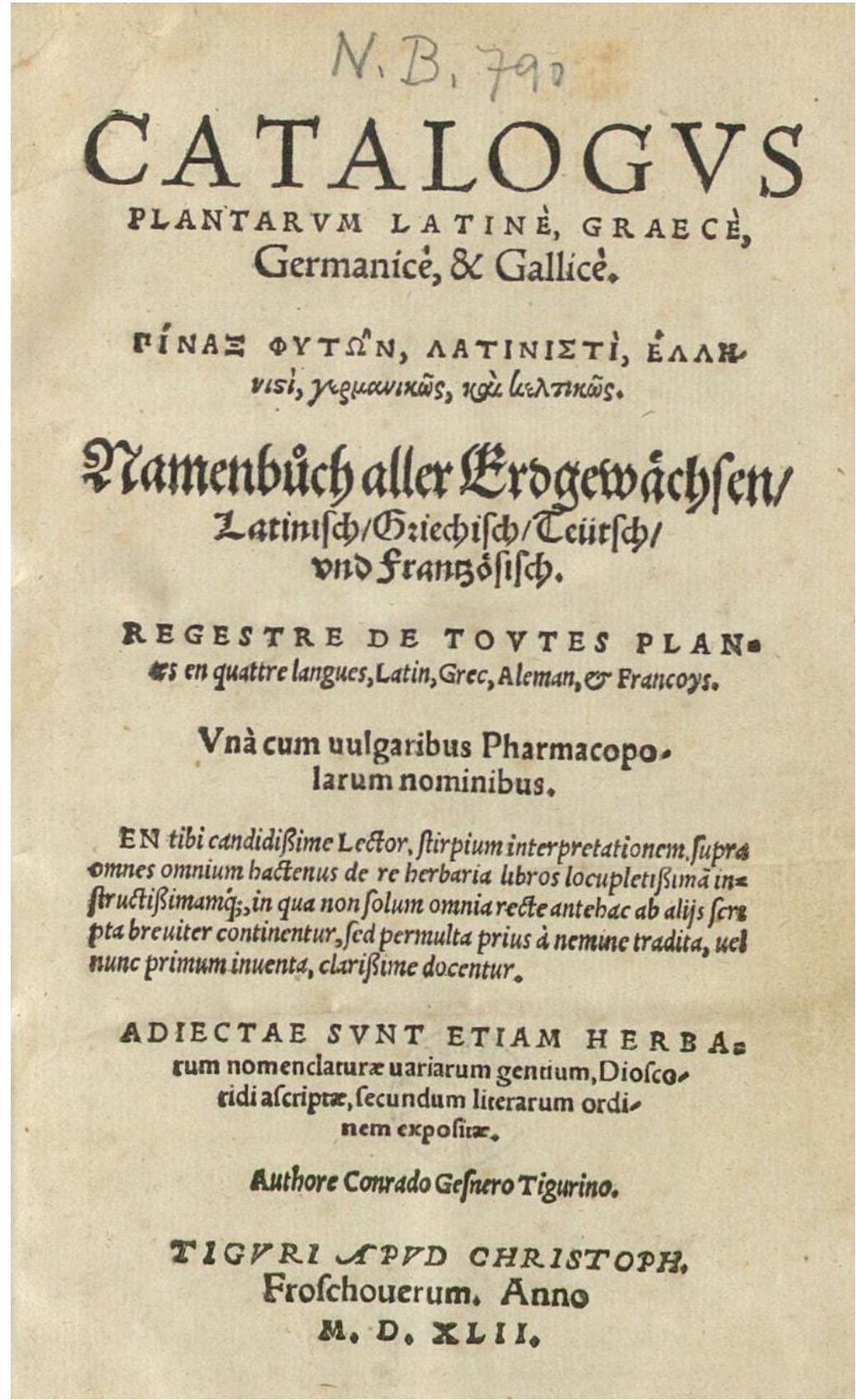

Figura 2 - Frontispício de Catalogus Plantarum

Fonte: GESNER (1542, f. 1r).

Acesso em: <http://www.e-rara.ch/zuz/content/pageview/847720>

O interesse de Gesner pela Botânica tem ligação direta com a existência do Alter Botanischer Garten ${ }^{3}$ (Antigo Jardim Botânico) de Zurique (FIG. 3). O Alter Botanischer Garten tem como origem o herbário privado de Gesner e oferece uma visão do conhecimento do Séc. XVI sobre plantas medicinais não só a partir do próprio Gesner, mas pelos seus contemporâneos.

\footnotetext{
${ }^{3}$ No jardim há um memorial de Conrad Gesner.
} 


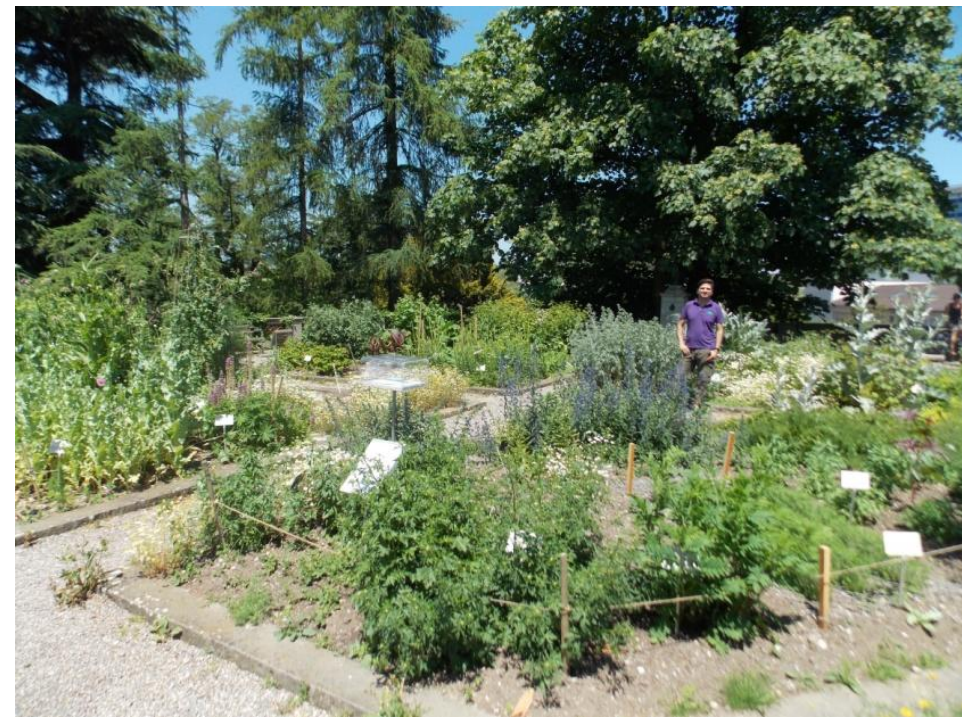

Figura 3 - Panorama do Alter Botanischer Garten (Zurique, Suíça)

Fonte: Arquivo pessoal (2013).

Gesner também se destacou na Filologia, tendo se debruçado sobre uma quantidade de edições críticas e traduções, além de se interessar por dialetos locais e vernáculos modernos.

No campo da Zoologia, publicou a imponente Historia Animalium (1551-1558 e 1587), considerado o ponto de partida para Zoologia Moderna. Na obra, Gesner faz a descrição de todos animais conhecidos, incluindo aqueles de natureza fantástica, como o Satyrus Marinus, ou o demônio do mar (FIG. 4). A obra é composta por inúmeras xilogravuras coloridas à mão e desenhadas a partir de observações pessoais do próprio Gesner (GESNER, 1558).

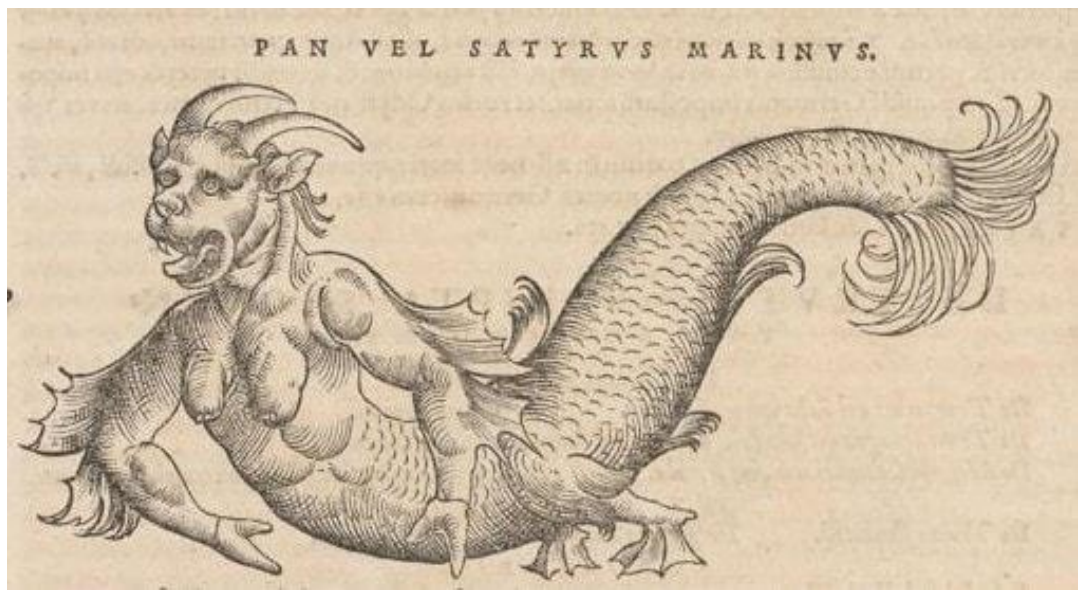

Figura 4 - Satyrus Marinus

Fonte: GESNER (1558, f. 1197r).

Acesso em: <http://www.e-rara.ch/zuz/content/pageview/5357506> 
A busca pelo conhecimento, contornada por uma educação humanista clássica, refletiu diretamente sobre a multiplicidade de campos em que Gesner atuou e publicou.

Consequentemente, Gesner criou uma rede de conhecimento não só a partir das obras publicadas, mas também pela rede de atores (eruditos, estudiosos, amigos e inimigos) que estabeleceu contato por meio de viagens e inúmeras correspondências ${ }^{4}$.

Apesar de uma vida marcada pela pobreza e pela frágil saúde, Conrad Gesner tornou-se um dos mais notáveis cientistas do período moderno. Na ocasião de sua morte, foi levado junto à sua coleção de documentos, manuscritos, livros e curiosidades naturais.

\section{Celebrações em torno dos 500 anos de nascimento de Conrad Gesner: experiências}

No ano de 2016 foi celebrado os 500 anos de nascimento de Conrad Gesner. De acordo com o site oficial (FIG. 5) das comemorações (GESSNER..., 2015), diversas exposições e eventos foram planejados em Zurique, Suíça, dos quais podemos destacar:

1-Exposição no Museu Nacional Suíço (em colaboração com a Biblioteca Central de Zurique);

2-Exposição no Museu de Zoologia da Universidade de Zurique;

3-Exposição no Zoológico de Zurique;

4-Exposição Gessner-Garten no Antigo Jardim Botânico de Zurique;

5-Exposição na Sukkulenten-Sammlung de Zurique;

6-International Congress Conrad Gessner;

7-Publicações (Facetten eines Universums: Conrad Gessner, 1516-2016 e Conrad Gessner (1516-1565));

8-Site.

\footnotetext{
${ }^{4}$ As correspondências de Gesner têm sido fontes históricas elementares para compreensão da história da comunicação científica na Europa do Séc. XVI.
} 


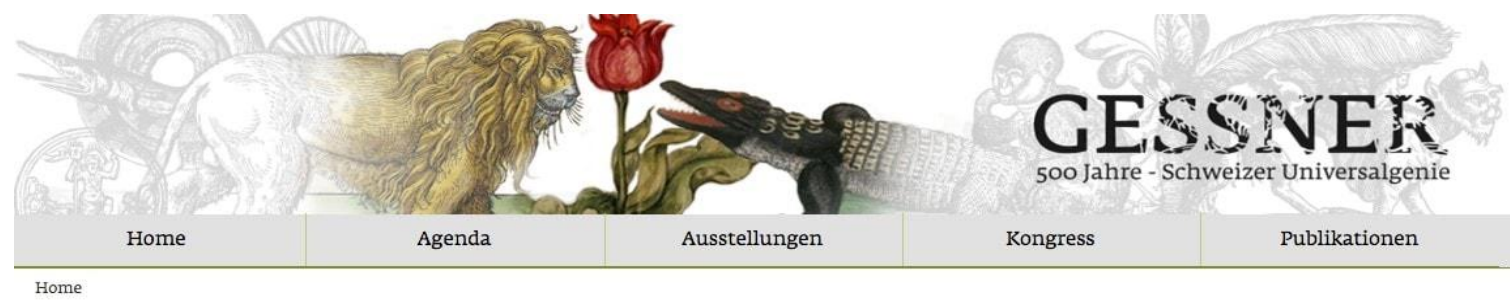

Willkommen zum 500. Geburtstag von Conrad Gessner!

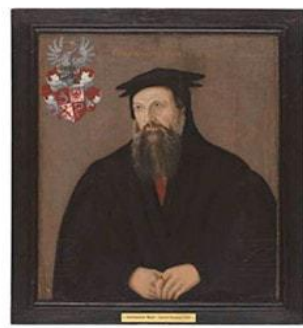

Im Jahr 2016 feiern wir den 500. Ceburtstag des berühmten Zürcher Mediziners, Naturforschers und Universalgelehrten. Er wirkte als Stadtarzt von Zürich, begründete die moderne beschreibende Zoologie und betrieb botanische Studien, indem er seine eigenen

Naturbeobachtungen höher gewichtete als die tradierten Erkenntnisse der Antike und des Mittelalters. Besonders bekannt geworden ist seine Historia animalium, in der er Vierbeiner, Vögel, Wassertiere sowie Schlangen und Skorpione zeichnete und beschrieb, darunter auch Fabelwesen wie das Einhorn. Und mit der Bibliotheca universalis schuf er die wichtigste Bibliografie der frühen Neuzeit, indem er versuchte, die infolge des Buchdrucks unübersehbar gewordene Bücher- und Informationsflut zu bewältigen.

Conrad Gessner ist am 16. März 1516 in Zürich geboren und am 13. Dezember 1565 ebenda gestorben. Zu seiner Erinnerung und Würdigung finden in Zürich im Jahr 2016 vielfältige Veranstaltungen statt:

Figura 5 - Site Oficial - Gessner 500 Jahre

Fonte: GESSNER (2015).

Acesso em: <http://www.gessner500.ch/>

A Exposição no Museu Nacional Suíço (FIG. 6) foi composta por documentos pessoais de Gesner e organizada a partir das inúmeras áreas do conhecimento em que ele atuou. Também se criou um ambiente dedicado à biografia e ao percurso científico de Gesner.

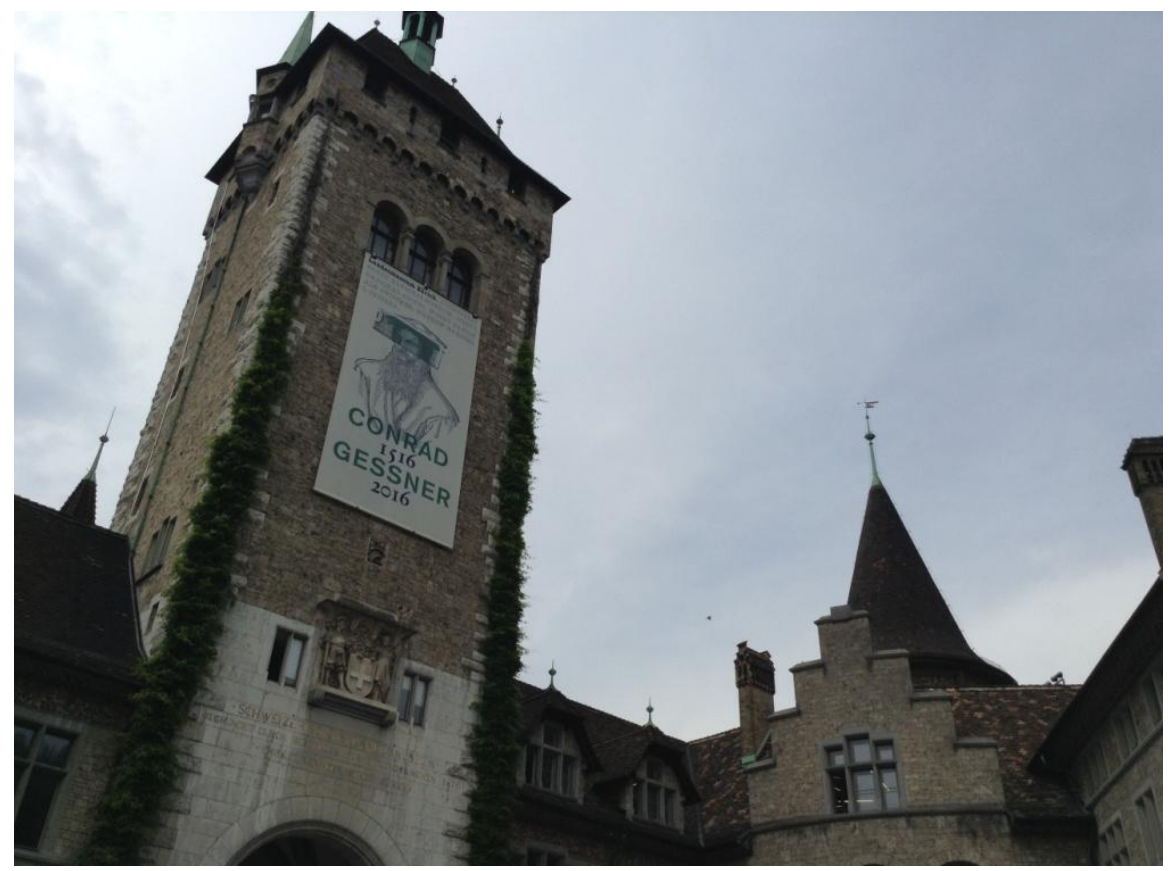

Figura 6 - Fachada do Museu Nacional Suíço - Exposição Conrad Gessner (1516-2016)

Fonte: Arquivo pessoal (2016). 
Em meio a desenhos botânicos e zoológicos, cartas, retratos, animais empalhados, livros, documentos contextualizadores da vida, obra e tempo de Gesner, destacou-se, do ponto de vista da Bibliografia, a exposição do exemplar pessoal de Bibliotheca Universalis de Conrad Gesner (Figura 7). Trata-se de um exemplar pleno de anotações de próprio punho (marcas de leitura), sinalizações dos fólios e em ótimo estado de conservação.

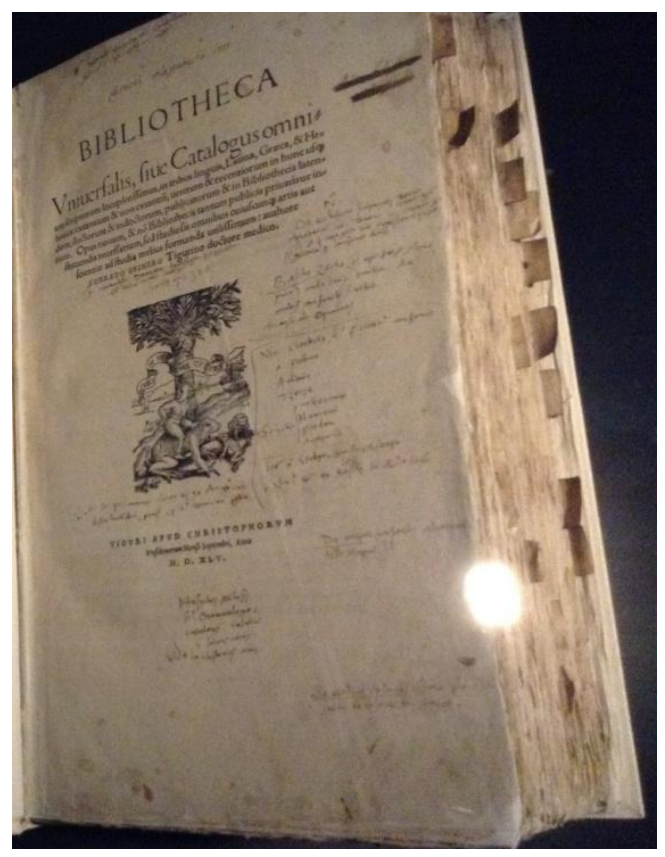

Figura 7 - Exemplar pessoal de Bibliotheca Universalis de Conrad Gesner Fonte: Arquivo pessoal (2016).

Na exposição do Museu Nacional Suíço também foi exibido um documentário ${ }^{5}$ realizado pela Universidade de Zurique e rodado em vários locais históricos por onde Gesner passou, como Augsburg, Bologna, Erlangen e Veneza.

Dos eventos em memória a Gesner, enfatizamos o International Congress Conrad Gessner, que foi organizado conjuntamente pela Universidade de Zurique e a Biblioteca Central de Zurique. Contou com quase cinquenta palestrantes provenientes da Bélgica, Brasil, Alemanha, Inglaterra, França, Itália, Japão, Canadá, Holanda, Áustria, Polônia, Rússia, Eslováquia, Hungria, EUA e Suíça. As línguas oficiais do Congresso foram alemão e inglês.

O Congresso foi realizado nas instalações da Faculdade de Teologia, pois neste edifício Gesner lecionou de 1541 até sua morte. A conferência de abertura do evento foi feita por Anthony Grafton (Universidade de Princeton) e versou sobre as relações entre Gesner e o médico inglês John Caius (1510-1573), evidenciada na preocupação de Gesner com a

\footnotetext{
${ }^{5}$ O breve documentário pode ser acessado em: <http://www.gessner500.ch/pages/home/film.php>.
} 
informação científica (LEU, 2016).

O evento reuniu especialistas e estudiosos ${ }^{6}$ e revelou a multiplicidade disciplinar e de interesses do polímata suíço.

Para Glardon (2016), os Estudos Gesnerianos ainda são, em grande medida, subdesenvolvidos. De forma geral, o que mais tem chamado atenção dos estudiosos tem sido as ilustrações de Gesner, proporcionando perspectivas interessantes sobre a história da arte e representação da natureza no Séc. XVI, bem como, estudos sobre a circulação de imagens, nas redes acadêmicas e comunicação do conhecimento no Renascimento.

A aproximação de pesquisadores de diferentes áreas do conhecimento tem contribuído para o fortalecimento dos Estudos Gesnerianos. Esta aproximação, ao lado da publicizacão das pesquisas em curso, foi um dos aspectos mais relevantes do Congresso ${ }^{7}$.

Em linhas gerais, as intervenções feitas no International Congress Conrad Gessner discutiram o pensamento Gesneriano sob o ponto de vista da Medicina, Zoologia, Botânica, Paleontologia, Linguística, Farmacologia, Teologia, História da Cultura, Comunicação Científica, História da Ciência e, obviamente, Bibliografia.

No contexto da Bibliografia e dos estudos históricos e culturais do livro, foram apresentados os trabalhos:

1) Gessner's Paratexts, de Ann Blair (Universidade de Harvard, EUA);

2) The Garden and the Library: Plants, Books, and Conrad Gessner, de Paul Nelles (Universidade Carleton, Canada);

3) Testimonianze della letteratura e della cultura ebraica nell'opera bibliografica di Conrad Gesner, de Fiammetta Sabba (Universidade de Bolonha, Itália);

4) Gessners Rezeption in Ungarn. Die Exemplare der Bibliotheca universalis in ungarländischen Gelehrtenbibliotheken (16.-18. Jahrhundert), de Attila Verók (Szeged, Hungria);

5) The Bibliotheca universalis and the Aldine Press, de Koichi Yukishima (Universidade de Waseda, Japão);

6) Dalla Teologia di Zwingli la legittimazione, in Gesner, di una Bibliografia universale, de Alfredo Serrai (Universidade La Sapienza de Roma, Itália);

7) Conrad Gessner in the tropics: the presence of Bibliotheca Universalis and Pandectae in two Brazilian heritages libraries, de Andre Vieira de Freitas Araujo (Universidade Federal do Rio de Janeiro, Brasil).

No conjunto, estes estudos demonstraram a dinâmica de Gesner para referenciar livros e localizar informações neles contidas, o tratamento

\footnotetext{
${ }^{6}$ Agradeço a Urs B. Leu, coordenador do Congresso e diretor do Departamento de Livros Raros da Biblioteca Central de Zurique, pelo convite para eu participar do Congresso como um dos locutores. Foi uma oportunidade impar para apresentar, compartilhar e debater meu interesse de pesquisa junto a importantes especialistas Gesnerianos.

${ }^{7}$ Um livro comemorativo com os trabalhos apresentados e debatidos está no prelo e será publicado em 2018.
} 
dado à informação bibliográfica, a extensão universal de seu projeto bibliográfico, bem como a presença de edições Gesnerianas originais em diferentes bibliotecas.

Considerando a perspectiva de que o estudo e a reflexão sobre a Bibliografia pode se desenvolver por meio de experiências empíricas e coletivas, vale destacar que no Brasil também tivemos oportunidade de lembrar os 500 anos de nascimento de Conrad Gesner. Tal referência ocorreu no III Seminário Internacional A Arte da Bibliografia: as faces culturais do gesto bibliográfico, realizado pela Escola de Ciência da Informação da UFMG (ECI-UFMG) e ocorrido em Belo Horizonte em 07 de dezembro de $2016^{8}$.

As comemorações dos 500 anos de nascimento de Conrad Gesner demonstraram a sua relevância histórica e científica para inúmeras disciplinas e abriram potenciais agendas de pesquisa.

Para percebermos a dimensão de Conrad Gesner à Bibliografia, partimos do ano de 2016 e nos direcionamos ao Séc. XVI para situarmos e discutirmos, de forma preliminar, dois aspectos subjacentes ao gesto bibliográfico Gesneriano: método e implicações epistemológicas.

\section{Do gesto bibliográfico ao método bibliográfico Gesneriano}

O método bibliográfico de Conrad Gesner decorre de seu gesto bibliográfico que demarca o teu perfil.

De acordo com Crippa (2016, p. 24), o gesto bibliográfico pode ser entendido como "[...] conjunto de teorias e práticas bibliográficas, cruzamento entre o campo do conceito (reflexões sobre tarefas, necessidades, atores que a bibliografia satisfaz e para quem ela opera) e o dos fazeres (que podemos identificar nos "atos" de seleção, registro, e organização de seus materiais)".

Gesner transita entre o conceito e o fazer e realiza, por excelência, um gesto bibliográfico na medida em que busca sentido à organização documentária e constrói técnicas a partir de tecnologias selecionadas a priori.

Compreender o gesto e o método de Gesner só é possível a partir da análise da estrutura documentária do projeto bibliográfico mais ambicioso na Europa Moderna: Bibliotheca Universalis.

Bibliotheca foi publicada em quatro partes, entre 1545-155: Bibliotheca Universalis (1545), Pandectae (1548), Partitiones theologicae (1549) e Appendix bibliothecae (1555).

Bibliotheca Universalis foi impressa em Zurique, em setembro de 1545, na tipografia Christoph Froschauer, em um in-folio de 631 folhas.

\footnotetext{
8 Para acesso ao programa e outras informações do III Seminário A Arte da Bibliografia, ver: http://www.bibliotecapublica.mg.gov.br/index.php/pt-br/noticias/170-iii-seminario-internacional-a-arte-dabibliografia-as-faces-culturais-do-gesto-bibliografico
} 
No frontispício de Bibliotheca figura o título de partida (FIG. 8) em que Gesner afirma o escopo da obra.

\section{BIBLIOTHECA}

Vniuerfalis, fiue Catalogus omnis um fcriptorum locupletiffimus, in tribus linguis, Latina, Græca, $8 \mathrm{He}=$ braica: extantium \& non extantiū, ueterum \& recentiorum in huncuf ${ }_{\beta}$ diem, doctorum \& indoctorum, publicatorum \& in Bibliothecis laten= tium. Opus nouum, \& nô Bibliothecis tantum publicis priuatisue in=

ftituendis neceffarium, fed ftudiof is omnibus cuiufcung $\not$ artis aut fcientix ad ftudia melius formanda utiliffimum : authore CONRADO GESNERO Tigurino doctore medico.

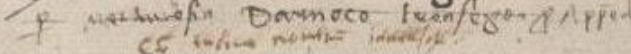

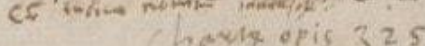

Figura 8 - Título de partida de Bibliotheca Universalis

Fonte: GESNER (1545, f. 1r).

Acesso em: <http://www.e-rara.ch/zuz/content/pageview/5079514>.

De acordo com o título de partida, a obra é uma:

Biblioteca universal ou catálogo muito completo de todos os escritores em três idiomas, latim, grego e hebraico, existentes e não mais existentes, antigos e mais recentes até esta data, eruditos e não eruditos, publicados e conservados nas bibliotecas. Uma obra inovadora e não apenas necessária para o estabelecimento de bibliotecas públicas e privadas, mas também muito útil para uma formação melhor de todos os estudiosos de qualquer arte e ciência. Autor: Conrado Gesner, zuriquense, médico/doutor de medicina (GESNER, 1545, f. 1r). ${ }^{9}$

Do ponto de vista estrutural, Bibliotheca Universalis é um catálogo alfabético-nominal que elenca 5031 autores de obras em latim, grego e hebraico. Está organizado por ordem alfabética do primeiro nome do autor e apresenta resumo e extrato dos documentos listados (FIG. 9). Uma lista por sobrenomes também acompanha o volume (SABBA, 2012).

\footnotetext{
${ }^{9}$ Agradeço imensamente a Erika Werner (Humboldt-Universität zu Berlin) pela tradução e pelos nossos diálogos acerca das passagens em latim.
} 


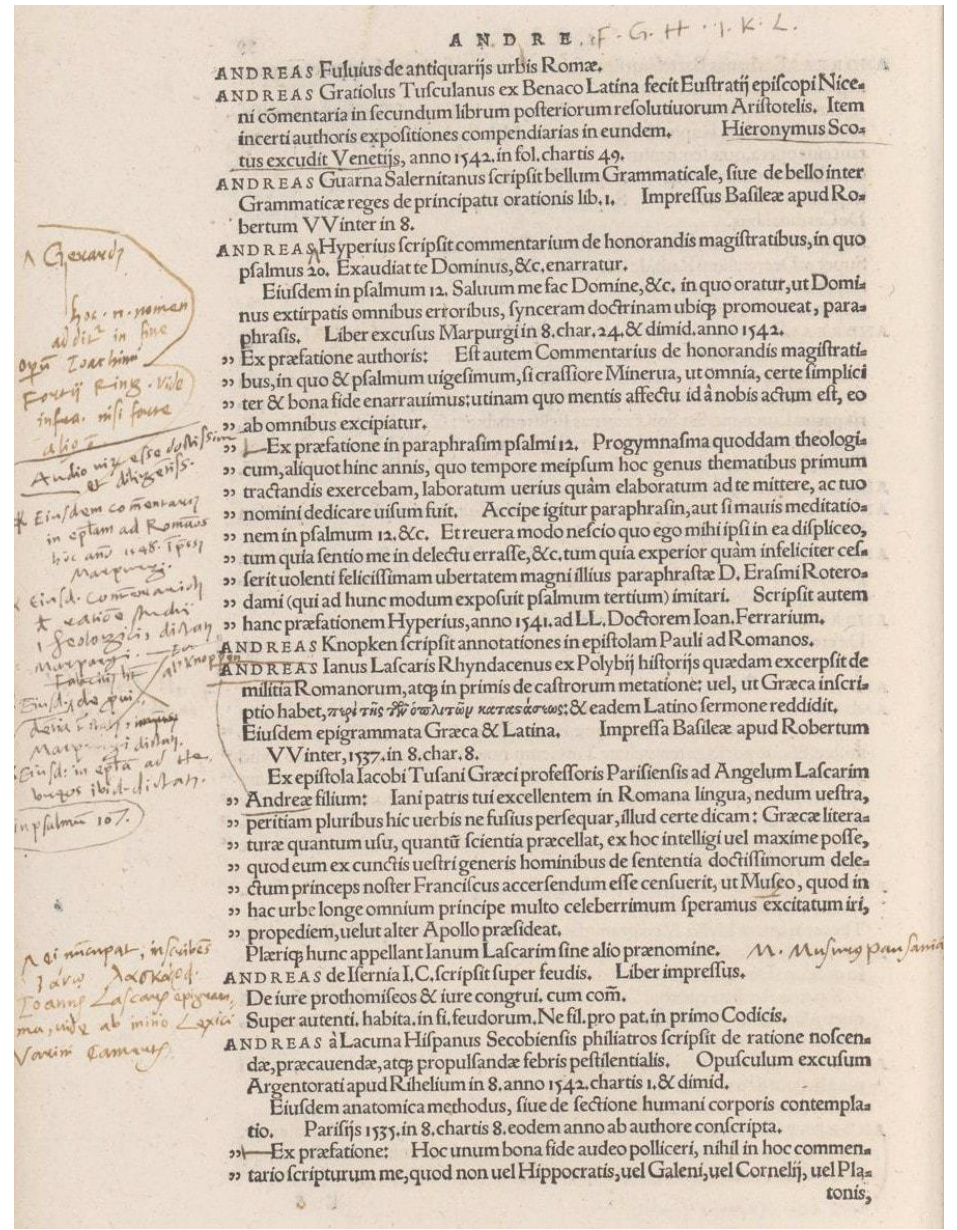

Figura 9 - Lista de nomes ordenados alfabeticamente e extratos dos documentos, a partir da entrada ANDRE

Fonte: GESNER (1545, f. 39v).

Acesso em: <http://www.e-rara.ch/zuz/content/pageview/5079607>

$\mathrm{Na}$ Epístola nuncupatória de Bibliotheca, Gesner relembra as inúmeras perdas bibliográficas sofridas pela humanidade e admite o seu sofrimento, perguntando-se sobre o destino de importantes e imponentes coleções bibliográficas, a exemplo da Biblioteca de Ptolomeu Filadelfo, Alexandria e Pérgamo. Também expõe sua preocupação em relação às perdas de coleções pela traça e pela umidade (GESNER, 1545).

Neste sentido, podemos afirmar que uma das motivações de Conrad Gesner para a concepção e materialização de seu projeto bibliográfico está no propósito de salvaguardar a memória da humanidade por meio de dispositivos bibliográficos.

Outro elemento chave de seu gesto bibliográfico é o fato de reunir, em uma única obra, fontes escritas em diversas partes da Europa que poderiam permanecer desconhecidas se não fosse a sua compilação e divulgação.

Em relação às fontes presentes em Bibliotheca, Gesner incluiu livros "[...] existentes e não mais existentes, antigos e mais recentes, eruditos e 
não eruditos, falsificados e atualmente desaparecidos" (GESNER, 1545, f. $3 r)$.

Bibliotheca abrange volumes publicados por eruditos antigos e contemporâneos a Gesner, bibliografias de outros autores, além de comentários, argumentos, prefácios e mesmo capítulos.

Sobre os prefácios, Gesner afirma que:

Partes dos prefácios, com frequências transcritas verbatim, fornecem indicações acerca do estilo do autor, da ocasião [de composição] do livro ou acerca do argumento ou de qualquer outra coisa que diga respeito à instituição da biblioteca. Eu li de fato inteiramente os prefácios de todos os livros que estavam a meu alcance e, dentre esses, selecionei somente as coisas que pareciam extraordinárias, assim como eu omiti todas as coisas supérfluas e ornamentais, muitas das quais estão normalmente nos prefácios para exibir o engenho [do autor] ou para elogiar alguém, em geral pelos seus escritos. Do mesmo modo, o leitor será aliviado de um grande ônus, ao não ter que ler os prólogos completos dos autores em suas obras e muito menos em outras obras de outros [autores], mas apenas as coisas selecionadas por mim. É por isso que eu transcrevi muitas partes desses prefácios, não tanto para o renome da presente obra, quanto porque os títulos e comentários dos outros livros eram então levados em conta, embora isso fosse incomum (GESNER, 1545, f. 4r).

A pesquisa realizada por Gesner para concepção e consolidação de Bibliotheca Universalis incluiu catálogos de casas tipográficas, listagens de bibliotecas, cartas de amigos, narrativas de homens eruditos e catálogos de escritores. Gesner visitou bibliotecas, sejam elas públicas ou privadas, na Alemanha e Itália.

A abrangência autoral inclui tanto homens doutos quanto aqueles desconhecidos. Portanto, para Gesner, todos "[...] são lembrados sem qualquer distinção/discriminação de profissão, religião ou de doutrina, simplesmente de acordo com a ordem das letras". (GESNER, 1545, f. 1v).

Interessante observarmos a indistinção que Gesner faz, pois ela vai ao encontro de sua postura humanista, cabendo ao leitor a avaliação e mesmo julgamento das fontes. Como Gesner afirma "Eu desejei relatar tanto, mas deixei a seleção e o julgamento dos livros para os outros" (GESNER, 1545, f. 3v).

Quanto à utilização da obra, Gesner (1545, f. 1v) propõe:

Deve-se entender que a utilização dela será como a dos léxicos: não apenas os próprios nomes dos autores foram arranjados em ordem, mas também assim foram identificados cada um dos livros deles e já que esse índice foi pontuado/empregado em toda obra, para que ele esteja imediatamente visível para quem desejar algo, [o leitor] pularia o que não desejar ler. 
Considerando a sua extensão e seu grau de universalidade, Bibliotheca poderia ser utilizada como uma obra de consulta para eruditos, não eruditos e também para as próprias bibliotecas. Estas poderiam utilizar Bibliotheca a partir de duas funções: 1) como uma "lista de desiderata" e 2) como um catálogo, bastando indicar ao lado do título registrado o seu código de localização dentro da biblioteca.

Enquanto Bibliotheca Universalis se ocupa de uma perspectiva descritiva dos documentos, tendo como referência de organização a ordem alfabética do primeiro nome do autor, a segunda parte da obra, denominada Pandectae (1548), nos apresenta uma perspectiva semântica dos documentos.

Podemos afirmar que é aqui que Gesner passa do gesto ao método, por conta da formulação de uma sistemática bibliográfica de maior complexidade. Em outras palavras, é nas Pandectae que vemos consolidado o que denominamos de método bibliográfico Gesneriano.

Pandectae foi impressa em Zurique, em 1548, também na tipografia Christoph Froschauer, em um in-folio de 374 folhas. Trata-se da exposição classificada dos documentos listados na primeira parte de Bibliotheca.

No frontispício das Pandectae, ou Vinte e um livros das Pandectas ${ }^{10}$ ou das Partições Universais de Conrado Gesner de Zurique, perito nas artes médicas e na filosofia (FIG. 10), Gesner apresenta o escopo da obra.

${ }^{10}$ Também entendido como Enciclopédias. 


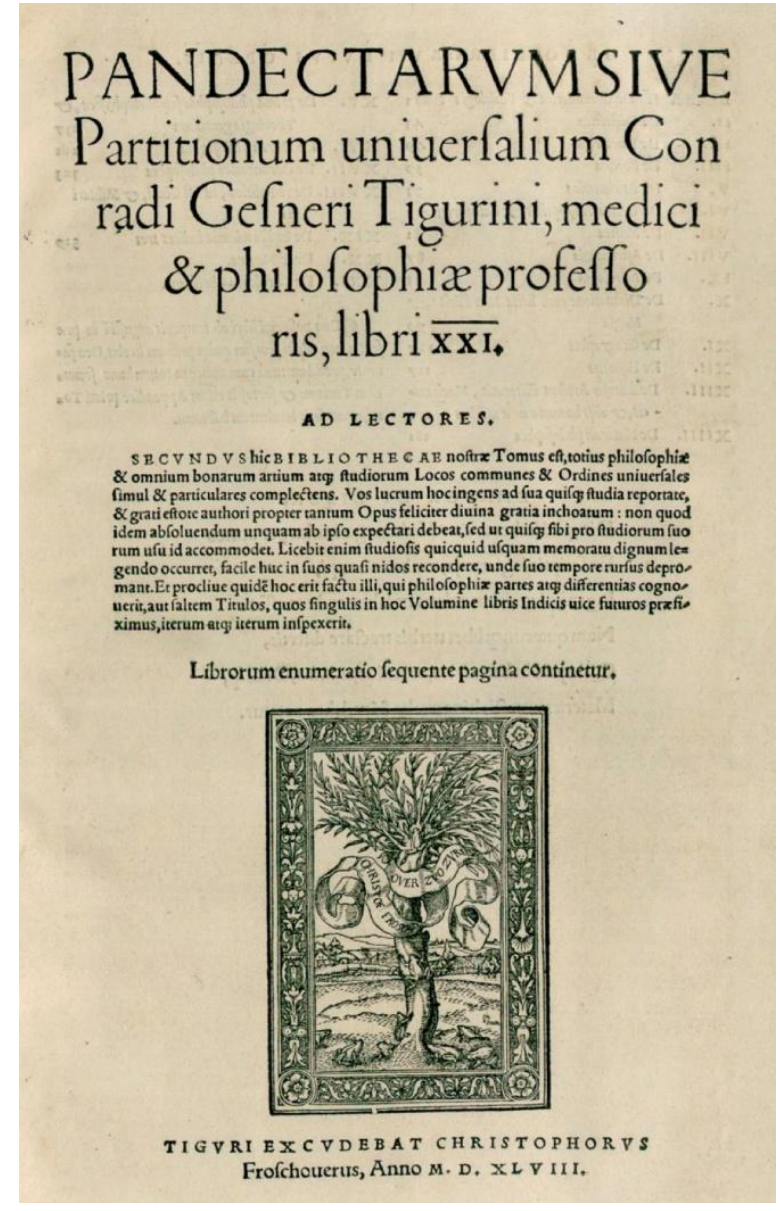

Figura 10 - Frontispício das Pandectae

Fonte: GESNER (1548, f. 1r).

Acesso em: <http://www.e-rara.ch/zuz/content/pageview/624960>

Segundo Gesner (1548, f. 1v):

Este é o segundo volume de minha Biblioteca, contemplando ao mesmo tempo as classes/hierarquias universais e as particulares e os lugares comuns de todas boas artes e estudos e de toda filosofia. Obtende vós este imenso ganho para quaisquer que sejam vossos estudos e sede gratos ao autor por tamanha [obra]. Esta obra foi auspiciosamente iniciada com uma graça divina: não porque é desejado pelo mesmo finalizá-la em algum momento, mas esta obra como que se adaptaria a eles de acordo com o que é requerido por seus estudos.

Enquanto Bibliotheca forma uma lista bibliográfica por autores, as Pandectae contemplam a exposição do conhecimento extraído dos livros da primeira parte.

As Pandectae estão baseadas segundo um esquema de repartição da Filosofia, considerada como todas as artes e ciências. As disciplinas podem ser Preparantes (isto é, ciências preparatórias) ou Substantiales (isto é, 
ciências substanciais); as primeiras se dividem em Necessariae e Ornantes. As Necessariae por sua vez em Sermocinales e Mathematicae. As Sermocinales compreendem: 1) Gramatica, 2) Dialetica, 3) Rhetorica, 4) Poetica. As Mathematicae compreendem: 5) Arithmetica, 6) Geometria, 7) Musica, 8) Astronomia, 9) Astrologia. As Ornantes: 10) Historiarum cognitio, 11) Geographia, 12) Divinationis et magiae cognitio, 13) Varia cognitio de artibus illiteratis, Mechanicis, et aliss humanae vitae utilibus. Le Substantiales são: 14) Physica, 15) Methaphysica et Theologia gentilium, 16) Ethica, 17) Oeconomica, 18) Politica, 19) Jurisprudentia, 20) Medicina, 21) Theologia Christiana (SERRAI, 1977).

As razões para tal divisão estão no fato de que as partições retomariam os âmbitos disciplinares nos quais Gesner acreditava que o conhecimento fosse composto.

O sistema de classificação das Pandectae inclui as classes referentes às sete artes liberais do Medievo, além das categorias de assuntos complementares e de interesse aos eruditos do Renascimento.

Em realidade, o que Gesner faz é expandir as sete artes liberais do Medievo, o que reflete sobremaneira na divisão do conhecimento ligada ao pensamento clássico do homem renascentista.

A partir deste referencial, Gesner (1548) elabora as Pandectae, constituindo a classificação do material documentário em XXI Partições, a saber:

$\begin{array}{llcc}\text { Livro I } & \text { : Sobre Gramática e a Filologia } & \text { fólio } 1 \\ \text { Livro II } & \text { : Sobre Dialética } & 43 & \\ \text { Livro III } & \text { : Sobre Retórica } & 49 & \\ \text { Livro IIII } & \text { : Sobre Poética } & 59 & \\ \text { Livro V } & \text { : Sobre Aritmética } & 73 & \\ \text { Livro VI } & \text { : Sobre Geometria, Ótica e Catóptrica } & 77 \\ \text { Livro VII } & \text { : Sobre Música } & 81 & \\ \text { Livro VIII } & \text { : Sobre Astronomia } & 87 & \\ \text { Livro X } & \text { : Sobre Astrologia } & 95 & \\ \text { Livro X } & \text { : Sobre Adivinhação, tanto com magia lícita quanto ilícita }\end{array}$

99
Livro XI : Sobre Geografia
107

Livro XII : Sobre Histórias

117

Livro XIII : Sobre diversas artes não eruditas, mecânicas e todas as outras úteis à vida humana 165

Livro XIV : Sobre Filosofia Natural 181

dos pagãos

Livro XV : Sobre a Filosofia Primeira ou Metafísica e sobre a Teologia

Livro XVI : Sobre Filosofia Moral 261

Livro XVII : Sobre Filosofia Econômica 303

Livro XVIII : Sobre Política, i.e. [assuntos] civis e militares 311

Livro XIX : Sobre Jurisprudência, três índices 319

Livro XX : Sobre Medicina

Livro XXI : Sobre Teologia Cristã 
A Partição/Livro XX projetado para apresentar o catálogo semântico da Medicina não foi publicada. Já a última Partição, denominada de Livro XXI Teologia, foi publicada separadamente em 1549.

No prefácio das Pandectae, Gesner argumenta que cada uma das partes/partição da obra foi dedicada àqueles que seriam como que seus patronos.

Segundo Gesner (1548, f. 2r), "[...] se trata mais de considerar em certas dedicatórias o argumento [de cada parte/livro] do que buscar patrocínio por meio delas especialmente quando eu as incluí com o desejo único de apenas relembrar os livros, que cada um deles teria escrito".

Do ponto de vista estrutural, as Pandectae estão organizadas da seguinte forma: cada classe representa um Livro que corresponde a uma Partição. Cada Livro, por sua vez, é organizado por: título do Livro (associado ao nome da respectiva Partição), a quem o Livro é dedicado e a exposição geral das subclasses subordinadas à classe que nomeia o Livro ou Partição.

Ou seja, a classificação é composta por 21 categorias (no contexto da obra, denominadas de Livros/Partições) que são subdivididas em classes subordinadas, ou seja, subclasses. Por fim, os títulos correspondentes a cada uma das subclasses são elencados.

Vejamos um exemplo deste sistema a partir do Livro Sobre Música, correspondente à Partição/Livro VII. No recto da página 81 (FIG. 11), observamos as seguintes informações na sequência:

- o título do Livro/Partição no topo da página: Partitionum universalum Liber VII. De Musica;

- a quem o livro é dedicado: "EXIMIO TYPOGRAPHO BASILIENSI HENRICO PETRO, DE BONIS STVDIIS OPTIME merito, domino \& amico suo charissimo, Conradus Gesnerus S.D.P [...]". Sobre Música é dedicado a Henrich Petri ou Henricus Petrus (1508-1579), um dos maiores tipógrafos da Basiléia que encabeçou a Officina Henricpetrina.

- exposição geral das subclasses ou seções que constituem o Livro VII: I. Trabalhos que lidam com vários gêneros de música; II Escritos sobre teoria modal e consonância; III Tratados e materiais introdutórios que lidam com vários aspectos teóricos e práticos da música - Grego, Latim e contemporâneo; IV Edições de música litúrgica; V Edições da música secular, principalmente latim, italiano e francês; VI Autoridades antigas e recentes sobre música; VII Trabalhos sobre instrumentos musicais; VIII Livros adicionais de polifonia impressa (apêndice) (BERNSTEIN, 1973). 


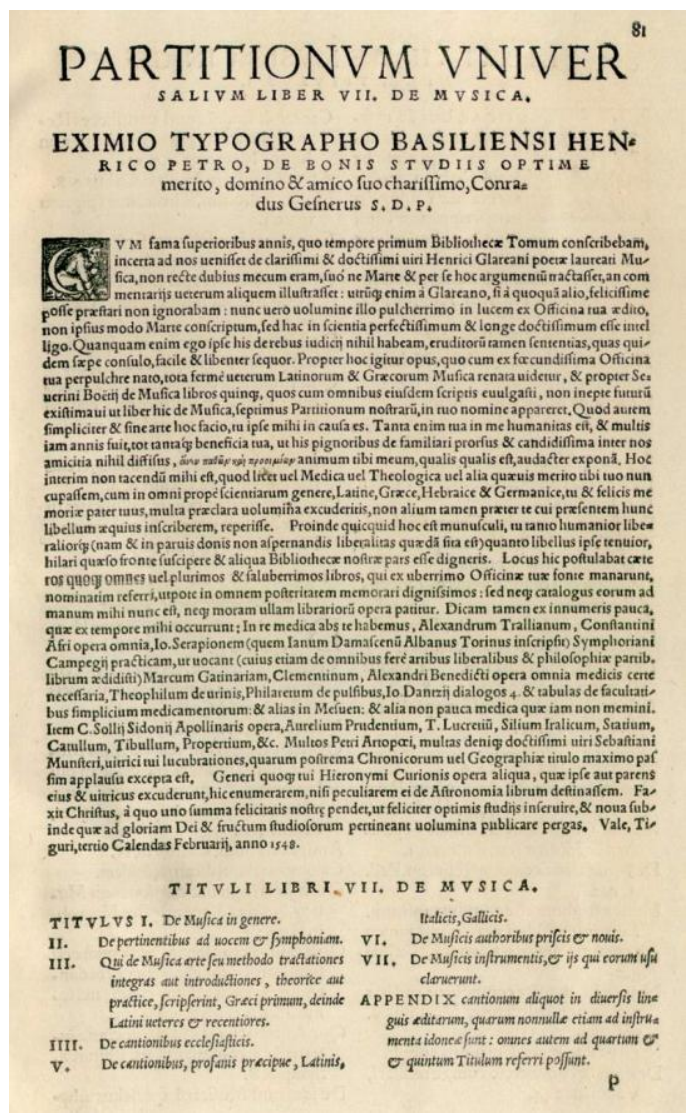

Figura 11 - Livro VII. Sobre Musica

Fonte: GESNER (1548, f. 81r).

Acesso em: < http://www.e-rara.ch/zuz/content/pageview/625132>

No verso do fólio 81 da Partição Sobre Música figura a lista de títulos no escopo de cada uma das VIII subclasses desta partição.

Como vimos, cada Livro representa uma Partição que estão representadas em Títulos. Cada Título está dividido em Partes. No caso do exemplo De Musica, temos VIII Partes (de I a VII) e um apêndice. As Partes contêm os Loci, seguidos de uma breve referência aos autores e às obras que lidam com os temas inseridos nesses Loci.

Este sistema é confirmado por Serrai e Sabba (2005, p. 56-57):

As Partições, ou classes principais são articuladas em Títulos; os Títulos estão subdivididos em Partes; e estas em Seguimentos. As Partes contêm os Loci, seguidos de uma brevíssima referência aos autores e às obras que trataram, há pouco, dos temas que se identificam ou se colocam naqueles Loci. As referências são acompanhadas com indicações concernentes ao livro e ao capítulo da obra, mas que aparece muitas vezes implícita e mencionada apenas sob o nome do autor.

No contexto de Gesner, os Loci são geralmente apresentados em uma sequência temática, o que significa que eles cobrem o escopo dos 
temas ligados a uma determinada Parte. Os Loci aparecem em ordem alfabética e podem ser tanto communes quanto particulares.

No Livro I: Sobre Gramática e a Filologia, Gesner define Loci communes ${ }^{11}$ :

São denominados, de forma absoluta, Loci communes, aqueles que não são circunscritos como parte da ciência nem da filosofia, mas apresentam um pouco de todas elas, e reúnem, a partir de todas as fontes possíveis, as [coisas] em particular que se referem a uma prática comum da vida e do dizer, de modo que possam ser utilizadas/examinadas por qualquer gênero retórico: essas coisas são ignoradas de todo pela matemática e, de forma mais sútil, pela filosofia. Muitos estudiosos coletam esses loci communes em uma compilação variada ao longo de suas anotações ou livros, separados por determinados títulos ou por temas. Alguns são arrolados em ordem alfabética, como [o faz] Domenico Nani em [sua obra] Polyanthea ${ }^{12}$, outros de acordo com os temas ou divisões da filosofia ou de acordo com qualquer outro critério. Os outros que se ocupam somente de uma única parte da filosofia, esses não serão denominados simplesmente loci communes, mas terão como complemento 'médicos' ou 'teológicos' e assim por diante. Eu os mencionarei em toda parte, ainda que eles sejam muitos, em que eles aparecerem. Já que a matéria a ser aprendida e referida é provida para o filólogo, para o orador e para o dialético a partir de toda espécie de loci communes, visto que não somente o nome é comum a diversos loci communes, mas também o tema [é comum] a muitos deles, convém que algumas coisas sejam consideradas. Por exemplo, acerca da ira. O estudioso da filosofia natural dirá, a partir da contemplação, que é algo acerca da respiração/vida, o médico, por sua vez, [que é algo] acerca das emoções, que alteram o corpo e sua saúde, e o estudioso de filosofia moral e o teólogo, por outro lado, encontrarão exemplos e acontecimentos acerca da ira a partir de fontes históricas. O que impede, portanto, que quem falar sobre a ira não utilize explanações e argumentos à maneira da oratória, ora para discordar ora concordando acerca de um tema a partir de diversos loci communes, de modo que as coisas não se confundam de todo? (GESNER, 1548, f. 23v-24r).

O que se observa aqui, é que Gesner adota um método comum no Renascimento, ou seja, o método dos Loci communes, que é, ao final, um método de leitura e de armazenamento de informações. Em uma concepção documentalista pode ser entendido como um método de indexação, posto que ocorre a extração de termos de um conjunto documentário e a sua representação por meio de palavras.

Neste método, são selecionadas as passagens de interesse, ligadas às retóricas das frases, argumentos dialéticos ou informações factuais.

\footnotetext{
${ }^{11}$ A tradução do termo Loci communes para o português é Lugares-comuns. Entretanto, no contexto dos Estudos Gesnerianos, utiliza-se o termo latino.

12 Uma antologia de citações, definições e etimologias retiradas da Bíblia, de obras gregas e latinas, poetas italianos e humanistas.
} 
Estas passagens são copiadas em um caderno, o Livro de Loci communes, e são agrupadas em rubricas apropriadas para facilitar a posterior recuperação e uso, principalmente na composição de um trabalho próprio.

De acordo com Blair (1992), estritamente definido, o Livro de Loci communes é uma inovação humanista, mas que, como a maioria das práticas do Renascimento, adaptou um conceito com um glorioso pedigree antigo para atender às necessidades contemporâneas, neste caso pedagógicas e de investigação.

Os Loci communes e particulares das Pandectae são extraídos de cada uma das partes das edições arroladas por Gesner (comentários, prefácios, etc.), mas ele também usou Livros de Loci de Maximus Planudes, Agathia etc, conforme observamos nesta passagem das Pandectae:

Ao contrário daqueles que escreveram os Loci communes, alguns explicaram com suas palavras o que outros pensaram sobre certo assunto. Alguns deles, que estão em maior número, nada fizeram além de compilar sentenças alheias, as quais, por outro lado, outros de algum modo encontraram [e] reproduziram em comentários sem ordem, como nosso Estobeu. Outros empregaram algum método de ordenação e subdividiram loci communes em particular em certos gêneros e espécies; visto que isso é mais difícil que o trabalho de coletar, assim de longe isso é o mais importante para alguns estudiosos, já que os frutos [desse trabalho] abundam. Há aqueles que empregaram o método da afinidade e oposição para diferenciálos, como em geral Estobeu. Alguns juntaram [Loci communes] a partir de obras em grego, alguns a partir de obras em latim, outros de ambas. Alguns utilizaram somente poetas, alguns livros em prosa, outros ambos. Ao contrário daqueles que [extraíram os Loci communes] dos poetas, alguns colheram sentenças a partir de obras completas. Alguns apenas coletaram epigramas inteiros sobre Loci communes, ou [epigramas] de autores diversos, como [fez] Máximo Planudes em sua Antologia, ou [epigramas] de um único autor, como eu no caso de Marcial. Já muitos copiaram sentenças inteiras dos autores, as quais algumas vezes são longas demais, como fez Estobeu. Eu preferi aqueles, que reduzem os ditos mais prolixos dos autores a uma forma breve de oração, eles que indicam ao leitor ou que o resto deve ser lido na própria obra do autor ou colocam apenas o início das palavras do autor, ou aqueles que certamente indicam apenas por meio de números que coisas, em quais livros ou em quais capítulos ou páginas seriam encontradas em obras em particular. Índices e Concordâncias, como eles as chamam, também escritos diligentemente, também seriam uma espécie de ordenação de loci communes. Certamente muitos índices de autores, se alguém os tiver juntado em uma única ordenação, teriam provido loci communes por si só de algum modo úteis, particularmente sobre aqueles livros que eu haveria de ler (GESNER, 1548, f. 24r). 
Gesner articula e dispõe os Loci communes acerca de todas as coisas do universo, apresentando-os dentro de 12 temas (FIG. 12), a saber: 1. Escritura; 2. Lei; 3. Deus; 4. Culto de Deus; 5. Criação; 6. Homem; 7. Cristo; 8. Igreja; 9. Sacramentos; 10. Magistrado; 11. Artes e 12. Virtudes e vícios.

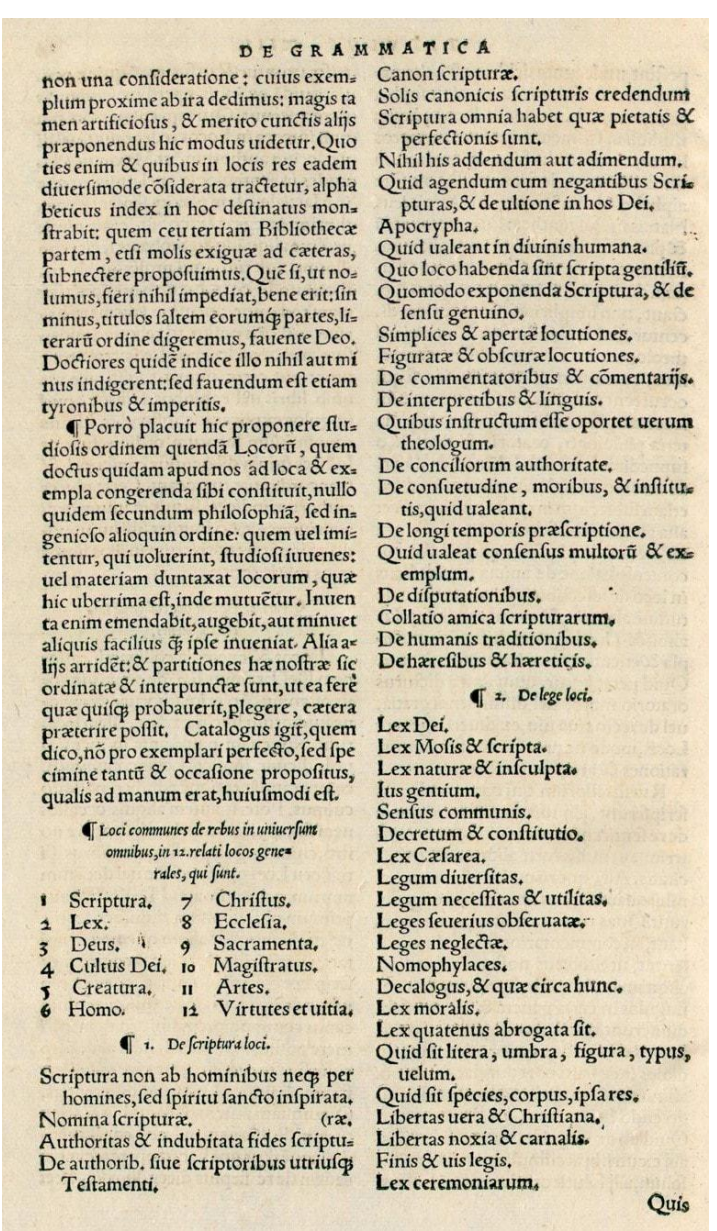

Figura 12 - Loci communes no Livro I: Sobre Gramática e a Filologia Fonte: GESNER (1548, f. 24v).

Acesso em: <http://www.e-rara.ch/zuz/content/pageview/625017>

Vejamos, a título de exemplo, dois tipos de Loci communes aplicados e subordinados aos 12 temas:

1-Loci communes acerca da Escritura: ex. 1 Autoridade e indubitável fé da escritura, ex. 2 Apócrifos;

2-Loci communes acerca da Lei: ex. 1 Lei de Deus, ex. 2 Lei moral;

3-Loci communes acerca de Deus: ex. 1 Divindade, ex. 2 Providência divina;

4-Loci communes acerca do Culto de Deus: ex. 1 Cerimônias, ex. 2 Templos; 
5-Loci communes da Criação: ex. 1 Criação, ex. 2 Reino do diabo;

6-Loci communes acerca do Homem; primeiro o que diz respeito à alma, depois o que diz respeito ao corpo: ex. 1 Homem, ex. 2 Alma;

7-Loci communes acerca de Cristo: ex. 1 Feitos de Cristo, ex. 2 Milagres de Cristo;

8-Loci communes acerca da Igreja: ex. 1 Sinagoga, ex. 2 Judéia;

9-Loci communes acerca dos Sacramentos: ex. 1 Batismo, ex. 2 Penitência;

10-Loci communes acerca do Magistrado: ex. 1 Democracia, ex. 2 Liberdade;

11-Loci communes acerca das Artes: ex. 1 [Artes] liberais, ex. 2 Gramática;

12-Loci communes acerca das Virtudes e dos vício: ex. 1 Virtude, ex. 2 Fé (GESNER, 1548).

De modo a sintetizar o sentido dos Loci, recorremos a Alfredo Serrai (2007, p. 13), que afirma que os Loci são

[...] conceitos, ou categorias, que expressam os temas e núcleos considerados significativos e representativos - como parte de uma das áreas de interesse e estudo de uma cultura particular - de uma obra, e que são, portanto, capazes de exprimir a informação e o conteúdo intelectual daquela obra. Em termos catalográficos os Loci, ou os índices semânticos de uma obra, são também são conhecidos como assuntos ou objetos (SERRAI, 2007, p. 13).

Gesner coloca em evidência a natureza dos Loci communes, e o âmbito no qual se dirigem, capturando a generalidade que mal caberia nos campos de saber mais específicos, os quais precisam coletar os Loci adequadamente expressivos (BALDI, 2014).

O aspecto basilar dos Loci communes é sublinhado, de tal modo, por Baldi (2014): oferta de categorias semânticas nos quais classifica obras de características filosóficas ou simplesmente de instrução moral e cotidiana, reforçando os substratos para os preceitos morais e sociais da própria existência.

A partir dos Loci, também conseguimos identificar as contribuições do método bibliográfico Gesneriano para a indexação enquanto processo de extração e representação de conceitos.

O processo de indexação, na visão Gesneriana, é apontado por Considine (2015, p. 490): "Você deve escrever seus pontos-chave em uma ou mais folhas de papel, em qualquer ordem, de um só lado, marcando as palavras pelas quais itens de várias palavras devem ser ordenados. Em seguida, você deve cortar as folhas de papel para que 
cada unidade de informação esteja em uma "tira separada" ". Neste processo, as tiras de papel deveriam ser tão estreitas e leves que elas se apegariam às tesouras que as cortavam.

Na figura 13 (FIG. 13), podemos ver uma lista de referências em preparação para a alfabetização, por Gesner. Esta é uma seção de uma única folha de papel em que Gesner copiou nomes de lugares africanos da Geografia de Ptolomeu.

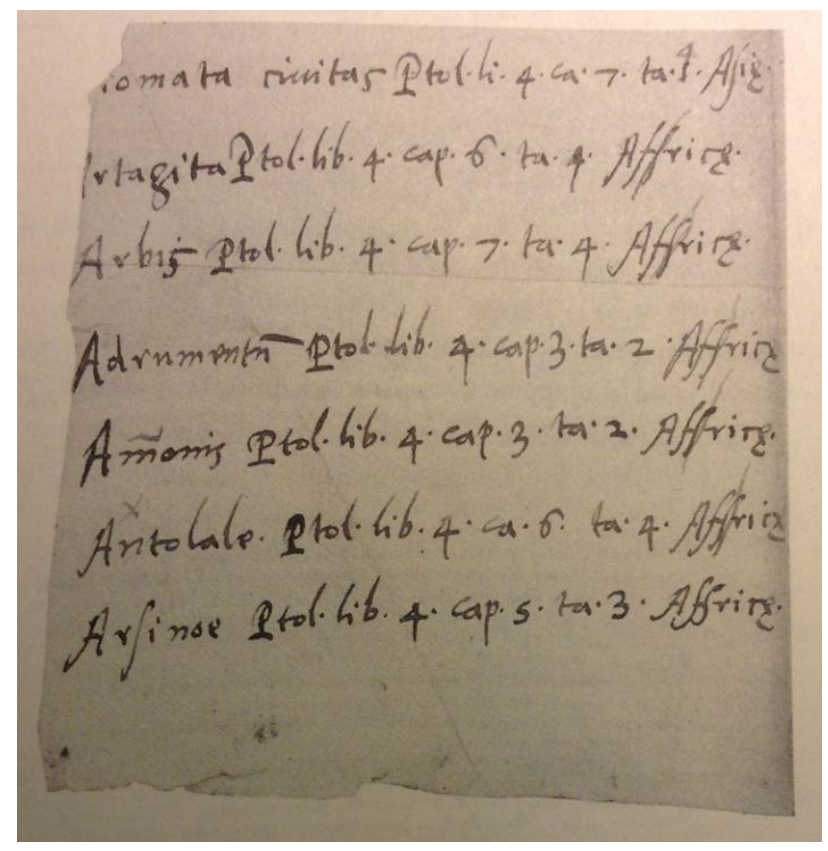

Figura 13 - Lista em preparação para alfabetização

Fonte: BLAIR (2010, p. 97).

Gesner foi o primeiro a recomendar a utilização de tiras para criar um índice alfabético: cada item a ser alfabetizado seria copiado em um único lado do papel que seriam cortados em deslizamentos, como vimos. Em um procedimento mais radical projetado para economizar o tempo e esforço de copiar, Gesner recomendava sempre que possível cortar a passagem diretamente do livro impresso (BLAIR, 2010).

Os índices elaborados em Bibliotheca Universalis e nas Pandectae são sofisticados e superiores comparados a outros índices contemporâneos de estudiosos.

A exemplo disso está no principal índice das Pandectae que foi impresso como a última parte de Partitiones theologicae (1549) (FIG. 14): ele ocupa 77 colunas sobre 26 fólios e contém em torno de 4000 entradas arranjadas alfabeticamente (WELLISCH, 1981). 


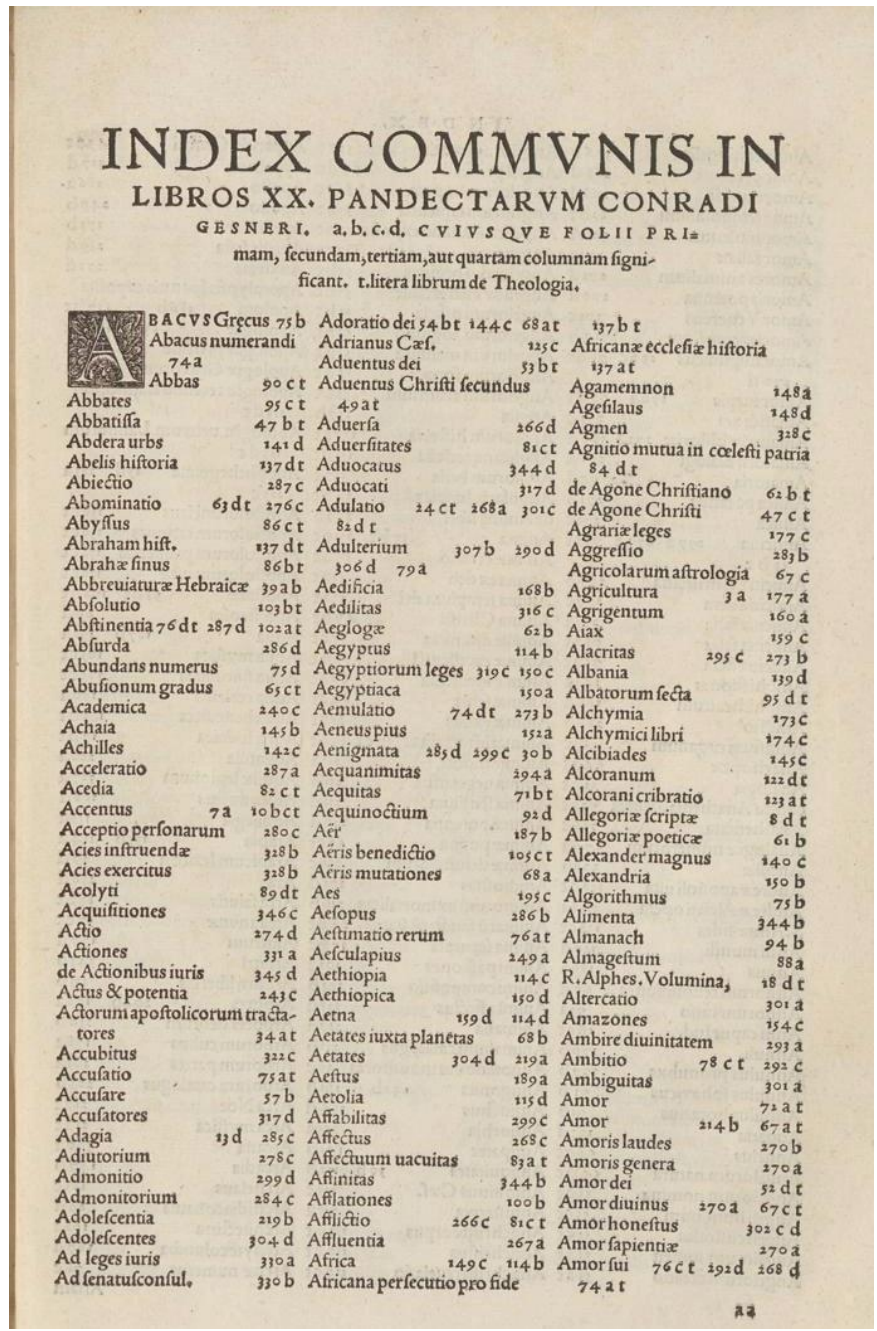

Figura 14 - Index communis in libros $X X$

Fonte: GESNER (1548, f. 159r).

Disponível em: <http://www.e-rara.ch/zuz/content/pageview/678610>

No Index communis in libros $X X$ observa-se junto às entradas arranjadas alfabeticamente tanto números quanto letras. Esta codificação se refere ao número da página e a letra se refere à coluna naquela página ( $a=$ primeira coluna, $b=$ segunda coluna, $c=$ terceira coluna, $d=$ quarta coluna). A letra "T" faz referência ao Livro de Teologia, isto é, o Livro XXI.

Gesner se destaca na elaboração de índices, uma vez que eles figuram em outras obras de sua autoria, sejam elas ligadas à Botânica, Farmacologia, Linguística etc.

Chegamos aqui no ponto central no método bibliográfico Gesneriano: em Bibliotheca Universalis, Gesner se vale de estratégias descritivas para elencar as obras (ordem alfabética por entrada de nome de autores e criação de uma lista separada com entrada pelos sobrenomes), enquanto que nas Pandectae se vale de estratégias semânticas, distribuindo e hierarquizando o conhecimento em um sistema de 21 classes e evidenciando o conteúdo das obras na forma de lugares semânticos ou Loci. 
Tanto a classificação quanto os Loci formam os elementos lógicos que articulam a estrutura das Pandectae e que, ao mesmo tempo, servem de base para a busca bibliográfica. É este o modelo conceitual que funda uma sistemática e mesmo uma disciplina que determinam as formas de se organizar, representar, recuperar e mediar os documentos na Europa Moderna do Séc. XVI.

Baldi (2014, p. 44) afirma que a reflexão sobre os Loci chega a intuir um aspecto adicional de profundidade notável:

[...] os Loci communes, além de serem categorias de classificação ético-filosófico, representam também aqueles macrotemas que podem ser tratados sob mais aspectos, realizando suas facetas, por sua vez subdivididas, nos quais formam um retículo conceitual sempre mais espesso, adequado para aproveitar e dominar a inteligência humana.

Esta seria uma intuição quase profética da moderna classificação categorial que é a base de catalogação por assunto e dos modelos conceituais de organização e representação documentária na contemporaneidade.

\section{Implicações epistemológicas do método bibliográfico Gesneriano: questões preliminares}

Diversos aspectos presentes em Bibliotheca e nas Pandectae conduzem à percepção de que o gesto bibliográfico de Gesner foi responsável pela formulação de um método: o método bibliográfico Gesneriano. Método este que possui características que o justificariam como tal, na medida em que:

1-Gesner adota procedimentos que seguem critérios sistemáticos em vista de um objetivo;

2-há regras, princípios e critérios, segundo os quais se desenvolve uma atividade (ou gesto) de ordem teórica e prática;

3-há um procedimento que se repete dentro de cada Livro/Partição da obra;

4-Gesner cria e propõe um sistema de classificação de base filosófica;

5-Gesner adota um método comum no Renascimento: o método dos Loci communes, que é um método de leitura, de armazenamento de informações e, sob o viés Gesneriano e documentário, um método de indexação.

6-Gesner formula um sistema de ordem descritiva e de ordem semântica; 
7-Gesner cria procedimentos adotados para organização, recuperação e mediação bibliográfica;

8-por fim, embora não sejam manuais de Bibliografia, Bibliotheca e as Pandectae tornam-se, por excelência, referencias monumentais de como se conceber e elaborar bibliografias, sejam elas de caráter universal ou especializadas.

O gesto bibliográfico Gesneriano impressiona por sua riqueza, considerando os desafios estruturais, econômicos, geográficos e técnicos da época de sua concepção e aplicação, marcada pela explosão e o caos informacional da Revolução Impressa.

Gesner, a partir de seu gesto bibliográfico, realiza justamente aquilo que se propõe a Bibliografia: para além de construir um mapa ordenado daquelas características que especificam e substanciam os documentos, a Bibliografia deve poder ser percorrida por critérios de busca, e esses se refletem, em geral, tradicionalmente, nos autores, nas obras e nas edições (SERRAI, 2001).

Com Gesner, se confirma e se assume a natureza da Bibliografia: disciplina que não se esgota na enumeração dos documentos, posto que contribui para esquematização destes, ao formular verdadeiros mapas documentários e do conhecimento.

Bibliotheca e as Pandectae se apresentam como documentos históricos fundamentais para compreensão das bases da organização documentária e do tratamento da informação, pois são, provavelmente, as mais antigas obras que discutem, em profundidade, técnicas bibliográficas, além de materializarem uma sensibilidade catalográfica e classificatória que é teorizada e aplicada com grande fineza lógica e com grande o senso de multidimensionalidade.

O método bibliográfico Gesneriano torna-se a matriz de onde se desenvolvem sistemas mais aprofundados e sofisticados de organização de documentos, independente de sua tipologia, natureza e densidade.

O gesto bibliográfico Gesneriano vai diretamente ao encontro do conceito de Bibliografia: disciplina constituída por interfaces teóricas, práticas e discursivas que fundamenta o tratamento documental, seja do ponto de vista de sua descrição, classificação, circulação e mediação (ARAUJO, 2015).

Por este ângulo, a Bibliografia pode ser entendida como disciplina referencial a disciplinas histórica e epistemologicamente correlatas como é o caso da Documentação, Biblioteconomia e Ciência da Informação.

\section{Considerações finais}

O ano de 2016 foi um ano significativo e histórico para os Estudos Gesnerianos, não somente pelas celebrações dos 500 anos de nascimento de Gesner, mas pelo fato de que, em meio às celebrações, inúmeros 
estudos foram realizados. Também se criou agendas de pesquisa, considerando que o polímata suíço ainda não foi explorado em sua completude.

A partir das celebrações, realizamos um movimento históricoretrospectivo para identificar o gesto bibliográfico Gesneriano a partir da concepção do maior projeto bibliográfico da Europa Moderna: Bibliotheca Universalis (1545) e as Pandectae (1548).

Defendemos a hipótese de Conrad Gesner realizou, por excelência, um gesto bibliográfico na medida em que promoveu uma reflexão sobre o conceito e os fazeres no escopo de suas obras bibliográficas.

O gesto bibliográfico Gesneriano teria fundamentado o próprio método bibliográfico Gesneriano, demarcado por preocupações documentárias de ordem descritiva e semântica. Em decorrência deste gesto, a Bibliografia adquire o seu estatuto enquanto disciplina.

Este estatuto se deve diretamente à problemática semântica que está no núcleo das Pandectae. Da proposta de um sistema de classificação em 21 partições, Gesner busca o núcleo semântico mais específico dos documentos a partir dos Loci.

Gesner propõe uma "arquitetura semântica" que encontra ulteriores divisões dentro dos livros até alcançar o núcleo semântico mais específico, dentro da seguinte sequência: Livros/Partições > Títulos > Partes > Parágrafos > Loci communes > Loci particulares (SABBA, 2016).

Para Serrai \& Sabba (2005), as Pandectae oferecem a vantagem de reunir uma estrutura universal de Loci communes, espelhando a totalidade da ciência e da arte, coisa que ninguém havia tentado até então.

Os ecos do gesto bibliográfico Gesneriano se materializam em duas frentes: 1) a Bibliografia assume sua natureza como disciplina a partir de Gesner e 2) observa-se ao longo dos séculos outros projetos universalistas de registro, organização, recuperação e mediação de documentos.

O desejo de Gesner (1545), registrado no prefácio de sua obra, é que outros pudessem segui-lo, o que evidencia o processo histórico que está por trás das diferentes formas de registro, organização, recuperação e mediação de documentos.

A partir destas premissas, a Bibliografia pode ser compreendida como "[...] estratégia para interpretação histórica e, ao mesmo tempo, futurística, da informação" (SABBA, 2015, p. 66).

É esta a dimensão histórico-interpretativa da informação, que perpassa pelo gesto e método bibliográfico Gesneriano, que não pode ser negligenciada para uma compreensão retrospectiva, crítica e ao mesmo tempo atual do campo informacional. 


\section{Dedicatória}

Dedico este artigo a Henrique Marcusso, amigo especial que partiu ao longo da redação deste texto e com quem travei relações afetivobibliográficas.

\section{Referências}

ARAUJO, A. V. de F. Conrad Gesner in the tropics: the presence of Bibliotheca Universalis and Pandectae in two Brazilian heritages libraries. In: LEU, Urs. (Org.). International Congress Conrad Gessner. Zürich: Universität Zürich, 2018 (no prelo).

. Pioneirismo bibliográfico em um polímeta do Séc. XVI: Conrad Gesner. Informação \& Informação, Londrina, v. 20, n. 2, maio/ago. 2015. Disponível em: <http://www.uel.br/revistas/uel/index.php/informacao/article/view/23127 >. Acesso em: 15 ago. 2015.

ARAUJO, A. V. de F.; CRIPPA, G. Confusa e irritante multidão de livros: relações entre o contexto histórico-informacional da Europa Moderna e a estrutura documentária de Bibliotheca Universalis, de Conrad Gesner. InCID: Revista de Ciência da Informação e Documentação, v. 7, p. 224241, $2016 . \quad$ Disponível em: <http://www.revistas.usp.br/incid/article/view/118774>. Acesso em: 20 fev. 2016.

- Cultura bibliográfica e documento no séc. XVI: Bibliotheca Universalis. In: COLÓQUIO INTERNACIONAL DA REDE MUSSI: as transformações do documento no espaço-tempo do conhecimento, 3., 2014, Salvador, BA. Anais... Salvador: Rede Mussi, 2014. CD Rom.

A dimensão histórico-epistemológica da Organização do Conhecimento: contributos da taxonomia gesneriana, Séc. XVI. In: GUIMARÃES, José Augusto; DODEBEI, Vera. (Org.). Organização do Conhecimento e Diversidade Cultural (Estudos Avançados em Organização do Conhecimento, v. 3). Marília: ISKO-Brasil; FUNDEPE, 2015, v. 3, p. 3746.

ARAUJO, A. V. de F.; CRIPPA, G.; SABBA, F. Semantic order in the 16th century: an introductory discussion of Conrad Gesner's Pandectae. In: GUIMARAES, José Augusto Chaves Guimarães. (Org.). Knowledge Organization for a sustainable world: challenges and perspectives for cultural, scientific, and technological sharing in a connected society. Proceedings of the Fourteenth International ISKO Conference, Sep. 27-29, 2016, Rio de Janeiro, Brasil. Würzburg: Ergon Verlag, 2016.

BALDI, D. Conrad Gesner, i Loci Communes dello pseudo Massimo Confessore e la Melissa del monaco Antonio. Bibliothecae.it, v. 3, n. 1, p. 19-61, 2014. Disponível em: 
<https://bibliothecae.unibo.it/article/view/5711>. Acesso em: 10 jun. 2017.

BERNSTEIN, L. F. The Bibliography of Music in Conrad Gesner's Pandectae (1548). Acta Musicologica, v. 45, fasc. 1, jan./jun.1973. pp. 119-163. Disponível em: <http://www.jstor.org/stable/932225>. Acesso em: 15 maio 2015.

BLAIR, A. Humanist methods in Natural Philosophy: the commonplaces book. Journal of the History of Ideas, v. 53, n. 4, p. 541-551, oct.-dec. 1992.

. Too much to know: managing scholarly information before the modern age. New Haven, CT: Yale University Press, 2010.

CONSIDINE, J. Cutting and pasting slips: early modern compilation and information management. Journal of Medieval and Early Modern Studies, v. 45, n. 3, p. 487-504, Sep. 2015.

CRIPPA, G. Entre arte, técnica e tecnologia: algumas considerações sobre a bibliografia e seus gestos. InCID: Revista de Ciência da Informação e Documentação, Ribeirão Preto, v. 7, p. 23-40, ago. 2016. ISSN 21782075. Disponível

em: <http://www.revistas.usp.br/incid/article/view/118748/116231>. Acesso em: 01 jun. 2017.

D. CONRADUS Gesnerus. [S.I.], [16--?]. Disponível em: <http://www.erara.ch/zuz/ periodical/titleinfo/12276926>. Acesso em: 01 jun. 2017.

GESNER, C. Bibliotheca universalis, sive, Catalogus omnium scriptorum locupletissimus in tribus linguis Latina, Graeca \& Hebraica: extantium \& non extantium, veterum \& recentiorum in hunc usque diem, doctorum \& indoctorum, publicatorum $\&$ in bibliothecis latentium : opus novum $\&$ non bibliothecis tantum publicis privatisue instituendis necessarium, sed studiosis omnibus cuiuscunque artis aut scientiae ad studia melius formanda utilissimum. Tiguri: apud Christophorum Froschouerum, 1545. Disponível em: <http://www.e-rara.ch/zuz/content/titleinfo/5079505>. Acesso em: 05 maio 2016.

. Catalogus plantarum latine, graeca, germanice \& gallice [...]: una cum vulgaribus pharmacopolarum nominibus [...]. Tigri: apud Christoph. Froschouerum, 1542. Disponível em: <http://www.erara.ch/zuz/content/titleinfo/847714>. Acesso em: 06 maio 2016.

. Conradi Gesneri medici Tigurini historiae animalium [...]. Tigri: apud Christophorum Froschouerum, 1558. Disponível em: <http://www.erara.ch/zuz/content/titleinfo/5356265>. Acesso em: 05 maio 2016.

- Pandectarum sive partitionum universalium Conradi Gesneri Tigurini, medici \& philosophiae professoris, libri XXI : Ad lectores. Secundus hic Bibliothecae nostrae tomus est, totius philosophiae \& omnium bonarum artium atque studiorum locos communes \& ordines 
universales simul \& particulares complectens [...]. Tiguri: excudebat Christophorus Froschouerus, 1548. Disponível em: <http://www.erara.ch/zuz/content/titleinfo/624958>. Acesso em: 05 maio 2016.

GESSNER: 500 Jahre - Schweizer Universalgenie. Zürich: Zentralbibliothek Zürich, 2015. Disponível em: <http://www.gessner500.ch/>. Acesso em: 22 jan. 2017.

GLARDON, P. Gessner Studies: state of the research and new perspectives on 16th-century studies in natural history. Gesnerus, v. 73, n. 1, p. 7-28, 2016.

LEU, U. B. Conrad Gessner-Kongress, Zürich, 6.-9. Juni 2016. Bibliothecae.it, v. 5 (2), p. 358-364, 2016. Disponível em: $<$ https://bibliothecae.unibo.it/article/view/6401>. Acesso em: 07 maio 2017.

SABBA, F. La 'Bibliotheca Universalis' di Conrad Gesner: monumento della cultura europea. Roma: Bulzoni Editore, 2012.

. Natura ed origini della Bibliografia: una prospettiva disciplinare per la contemporaneità. InCID: Revista de Ciência da Informação e Documentação, Ribeirão Preto, v. 7, p. 99-133, ago. 2016. Disponível em: <http://www.revistas.usp.br/incid/article/view/118778>. Acesso em: 09 sep. 2016.

SERRAI, A. Il cimento dela bibliografia. Milano: Sylvestre Bonnard, 2001. - Le classificazioni: idee e materiali per una teoria e per una storia. Firenze: Leo S. Olschki Editore, 1977. . I Pandectae di Conrad Gesner. Bibliotheca, 1, p. 11-37, 2007.

SERRAI, A.; SABBA, F. Profilo di Storia della Bibliografia. Milano: Edizioni Sylvestre Bonnard, 2005.

WELLISCH, H. How to make an index - 16th century style: Conrad Gesner on index and catalogs. International Classification, Frankfurt, v. 8, n. 1, p. 10-15, 1981. 